DOI: $10.5965 / 25946412222018003$

\title{
ASSISTÊNCIA NAS UNIDADES DE ESTRATÉGIA DE SAÚDE DA FAMÍLIA NA PERCEPÇÃO DOS USUÁRIOS DO SERVIÇO DE SAÚDE MENTAL
}

\author{
Nairan Morais Caldas \\ Universidade Estadual de Santa Cruz (UESC) \\ nairanmorais@yahoo.com.br
}

\begin{abstract}
Resumo
O estudo objetivou conhecer a percepção dos usuários do serviço de saúde mental sobre a assistência nas Unidades de Estratégia de Saúde da Família. Tratou-se de uma pesquisa com abordagem qualitativa, de caráter exploratório, por meio da aplicação de entrevista semiestruturada individual aos usuários do Centro de Atenção Psicossocial de Ilhéus/Bahia. A análise se deu a partir da emergência de informações recorrentes que foram codificadas em categorias. Em seguida, procurou-se referencial teórico que abarcasse essas categorias, relacionando com o que foi levantado. Verificou-se nos discursos: uma deficiência na formação de vínculo entre os usuários e as equipes da Estratégia de Saúde da Família; que suas demandas clínicas, na maioria, são atendidas com dificuldades, e; um despreparo das equipes quando se trata das necessidades em saúde mental, imperando o encaminhamento e até mesmo a recusa de atendimento. Diante do exposto, fica evidente a importância de se realizar estudos mais aprofundados sobre a temática e ampliar o conhecimento sobre a saúde mental na Atenção Básica, assim como o conhecimento do usuário com transtorno mental, acerca dos seus direitos como cidadão de usufruir dos serviços da Estratégia de Saúde da Família e de participar do seu próprio tratamento.
\end{abstract}

Palavras-chave: Assistência. Estratégia de Saúde da Família. Saúde Mental. Percepção.

\section{ASSISTANCE IN THE FAMILY HEALTH STRATEGY UNITS IN THE MENTAL HEALTH CARE USER PERCEPTION}

\begin{abstract}
The study aimed to know a perception of users of the mental health service on the assistance in the Units of Family Health Strategy. This was a research with a qualitative, exploratory approach, through the application of an individual semi-structured interview to the users of the Psychosocial Attention Center from Ilhéus/Bahia. The analysis came from the emergence of recurrent information that was codified into categories. Next, a theoretical reference was made that encompasses these categories, relating to what was raised. The speeches were: a deficiency in the formation of a link between the users and the teams of the Family Health Strategy; that their clinical demands, in the majority, are met with difficulties, and; an unprepared team when it comes to mental health needs, requiring referral and even denial of care. In view of the above, it is evident the importance of conducting more in-depth studies on the subject and increasing the knowledge about mental health in Primary Care, as well as the knowledge of the user with mental disorder, about their rights as a citizen to enjoy the services of the Family Health Strategy and to participate in its own treatment.
\end{abstract}

Keywords: Assistance. Family Health Strategy. Mental health. Perception.

Cidadania em Ação: Revista de Extensão e Cultura, Florianópolis (SC), v. 2, n.2, jul./dez. 2018. 


\title{
ASISTENCIA EN LAS UNIDADES DE ESTRATEGIA DE SALUD DE LA FAMILIA EN LA PERCEPCIÓN DE LOS USUARIOS DEL SERVICIO DE SALUD MENTAL
}

\begin{abstract}
Resumen
El estudio objetivó conocer la percepción de los usuarios del servicio de salud mental sobre la asistencia en las Unidades de Estrategia de Salud de la Familia. Se trató de una investigación con abordaje cualitativo, de carácter exploratorio, por medio de la aplicación de entrevista semiestructurada individual a los usuarios del Centro de Atención Psicosocial de Ilhéus/Bahia. El análisis se dio a partir de la emergencia de informaciones recurrentes que fueron codificadas en categorías. A continuación, se buscó referencial teórico que abarcara esas categorías, relacionando con lo que fue levantado. Se verificó en los discursos: una deficiencia en la formación de vínculo entre los usuarios y los equipos de la Estrategia de Salud de la Familia; que sus demandas clínicas, en su mayoría, son atendidas con dificultades, y; un despreparo de los equipos cuando se trata de las necesidades en salud mental, imperando el encaminamiento e incluso el rechazo de atención. Ante lo expuesto, queda evidente la importancia de realizar estudios más profundos sobre la temática y ampliar el conocimiento sobre la salud mental en la Atención Básica, así como el conocimiento del usuario con trastorno mental, acerca de sus derechos como ciudadano de usufructuar de los servicios de la Estrategia de Salud de la Familia y de participar de su propio tratamiento.
\end{abstract}

Palabras clave: Asistencia. Estrategia de Salud de la Familia. Salud mental. Percepción. 


\section{INTRODUÇÃO}

O foco principal da Reforma Psiquiátrica é o processo de desinstitucionalização, com principal objetivo de reduzir o número de leitos nos manicômios e hospitais psiquiátricos e programar uma rede de serviços substitutivos com base territorial (TANAKA; RIBEIRO, 2009). Essa rede substitutiva, a Rede de Atenção Psicossocial (RAPS), criou serviços de atenção com o objetivo de reinserir os indivíduos com transtornos mentais no convívio social, diversificando os serviços de cuidado e proporcionando um modelo de atenção que passa a ter como meta o exercício da cidadania, além do controle dos sintomas. Nesse sentido, a Atenção Básica também compõe a RAPS, atuando como pilar de promoção e proteção da saúde e de cidadania (BRASIL, 2013).

Atenção Básica, segundo o Ministério da Saúde, especifica-se como um conjunto de ações de saúde, que englobam: a promoção e proteção da saúde, prevenção de agravos, diagnóstico, tratamento, reabilitação, redução de danos e manutenção da saúde, tendo como meta desenvolver uma atenção integral que tenha resultado na situação de saúde e autonomia das pessoas, tanto no âmbito individual, quanto no coletivo (BRASIL, 2012).

$\mathrm{Na}$ intenção de pôr em prática a realização dessas especificidades, o primeiro acesso das pessoas ao Sistema Único de Saúde (SUS) deve ser, preferencialmente, pela Atenção Básica, inclusive àqueles indivíduos que necessitam de um cuidado em saúde mental. Além disso, ressalta-se que mesmo os indivíduos que são acompanhados pela RAPS devem continuar sendo acompanhados pelas unidades básicas e/ou pelas Equipes de Saúde da Família (ESF), visto que, para além das necessidades psiquiátricas, essas pessoas necessitam continuar com um acompanhamento de suas demandas clínicas (BRASIL, 2013).

Contudo, a dicotomia ainda vigente entre corpo e mente, e, consequente separação entre demandas psiquiátricas e clínicas, tem afetado a assistência às pessoas com transtorno mental nesses serviços, sendo relegado a essas o direito à assistência na atenção primária, principalmente nas Unidades de Saúde da Família (USF). Em comparação a outras ações assistenciais relacionadas às demais áreas de saúde realizadas pelos profissionais da ESF, o que se observa é que a atenção aos indivíduos usuários do serviço de saúde mental fica postergada a segundo plano (JUNQUEIRA; PILLON, 2011).

Frente a esse quadro, juntamente com a escassez de estudos que enfoquem a percepção desses usuários a assistência oferecida pela ESF, tem-se como questão norteadora: como os indivíduos com transtornos mentais percebem a assistência recebida nos serviços da Estratégia

Cidadania em Ação: Revista de Extensão e Cultura, Florianópolis (SC), v. 2, n.2, jul./dez. 2018. 
de saúde da família?

Assim sendo, essa pesquisa teve como objetivo conhecer a percepção dos usuários do serviço de saúde mental sobre a assistência nas Unidades de Estratégia de Saúde da Família. A justificativa para sua realização se dá pela relevância de se ter conhecimento de como os usuários percebem a prestação desses serviços, de acordo com suas demandas psiquiátricas e/ou clínicas, como forma de incentivá-los a participar do seu próprio tratamento, assim como preconizado pelo Ministério da Saúde na Política Nacional da Saúde Mental (TANAKA; RIBEIRO, 2009).

Visa também a contribuir para o reconhecimento das equipes como produtoras de cuidados em saúde mental, fortalecendo dessa maneira, o que vem sendo preconizado pela Reforma Psiquiátrica e pela Política Nacional de Atenção Básica, no que diz respeito à assistência integral, universal e equânime.

\section{MÉTODOS}

Pesquisa qualitativa, exploratória realizada no Centro de Atenção Psicossocial II (CAPS II) do município de Ilhéus-Ba.

Os sujeitos compreenderam 15 usuários, sendo 12 mulheres e 3 homens, com idade entre 29 e 67 anos. Foram estabelecidos como critérios para participarem da pesquisa, ter idade igual ou superior a 18 anos; estar cadastrado no CAPSII há no mínimo dois anos; ser autônomo na realização das atividades de vida diária (atividades laborais, estudo, autocuidado entre outros); frequentar, no mínimo duas vezes ao ano o serviço de Atenção Básica, tendo assim mais condições de relatar suas experiências na perspectiva de uma pesquisa qualitativa.

Como critério de exclusão foi definido: aqueles indivíduos que no momento da coleta de dados apresentassem qualquer alteração psíquica ou que estivessem sob efeito de medicamentos que gerassem alterações na sua orientação no tempo e espaço. Ressalta-se que a equipe multiprofissional do CAPS II também auxiliou na escolha dos sujeitos, visto que esta possui contato diariamente com os mesmos.

Antes de proceder à coleta de dados, foi estabelecido contato com a secretaria de saúde do município e equipe do CAPSII cumprindo, os trâmites legais. Após esse contato inicial, os usuários foram convidados para uma roda de conversa para explicitações sobre a pesquisa e, a partir daí, assinaram o Termo de Consentimento Livre e Esclarecido (TCLE). Para a coleta foi utilizada a técnica da entrevista semi-estruturada, com um roteiro previamente elaborado. As

Cidadania em Ação: Revista de Extensão e Cultura, Florianópolis (SC), v. 2, n.2, jul./dez. 2018. 
entrevistas foram gravadas e transcritas após sua realização. As informações foram coletadas nos meses de maio e junho de 2017.

Através dos depoimentos, procedeu-se à análise interpretativa das falas, buscando atender aos objetivos do estudo. Dessa maneira, realizou-se a leitura dos depoimentos transcritos, utilizando para tanto a técnica de análise de conteúdo de Bardin, por permitir “[...] a percepção de conteúdos latentes e intuições não passiveis de quantificação [...]" (BARDIN, 2009). A partir da emergência de informações recorrentes, houve a codificação das mesmas em duas categorias temáticas.

As categorias temáticas deste estudo constituem, portanto, categorias empíricas, tendo como objetivo fornecer uma representação simplificada dos dados. Após a determinação das categorias, foram elaboradas as subcategorias. Essas são apresentadas e discutidas nos resultados.

Por questões éticas, cada participante foi identificado pela letra $\mathrm{P}$ seguida por números de 01 a 15. O projeto foi aprovado pelo Comitê de Ética em Pesquisa da Universidade Estadual de Santa Cruz sob número 2.042.739, em 2017, respeitando os princípios normativos para a pesquisa com seres humanos, compreendidos na Resolução nº 466, de 12 de dezembro de 2012.

\section{RESULTADOS E DISCUSSÃO}

Da análise das questões especificas e norteadoras da entrevista, emergiram duas categorias temáticas fundamentais que se encontram sinteticamente expostos no quadro seguinte (Quadro 1), juntamente com a análise articulada com a literatura.

Quadro 1- Categorias temáticas

\begin{tabular}{|l|l|}
\hline \multicolumn{1}{|c|}{ CATEGORIAS } & \multicolumn{1}{|c|}{ SUBCATEGORIAS } \\
\hline $\begin{array}{l}\text { Percepção dos usuários do serviço de saúde } \\
\text { mental sobre a assistência nas Unidades da } \\
\text { Estratégia de Saúde da }\end{array}$ & $\begin{array}{l}\text { Relações interpessoais X Assistência frustrante } \\
\text { Experiência positiva X negativa tanto na assistência } \\
\text { clínica quanto na assistência em saúde mental }\end{array}$ \\
$\begin{array}{l}\text { Desconhecimento da ESF como porta de entrada na } \\
\text { assistência em saúde mental }\end{array}$ \\
\hline
\end{tabular}

Cidadania em Ação: Revista de Extensão e Cultura, Florianópolis (SC), v. 2, n.2, jul./dez. 2018. 


\begin{tabular}{|l|l|}
\hline $\begin{array}{l}\text { Facilidades e dificuldades que corroboram } \\
\text { na qualidade da assistência na visão dos } \\
\text { usuários. }\end{array}$ & $\begin{array}{l}\text { Facilidades: } \\
\text { Características pessoais dos profissionais como } \\
\text { facilitadoras na qualidade da assistência. } \\
\text { Dificuldades: }\end{array}$ \\
& $\begin{array}{l}\text { Prevalência do modelo biomédico } \\
\text { Desconhecimento dos profissionais }\end{array}$ \\
& Fabre as intervenções em saúde mental \\
& \\
\hline
\end{tabular}

Fonte: Dados da pesquisa (2017).

\section{CATEGORIA 1: Percepção dos usuários do serviço de saúde mental sobre a assistência}

\section{nas unidades de estratégia de saúde da família}

Foi possível identificar que, na percepção dos usuários, a assistência nas unidades de ESF perpassa por questões relacionadas a: relações interpessoais em contraposição a uma assistência frustrante; a experiência positiva em paralelo com a assistência negativa, tanto na assistência clínica quanto na assistência em saúde mental; e desconhecimento dos usuários quanto a ESF ser a porta de entrada na assistência em saúde.

A percepção individual de quem usufrui dos serviços de saúde é complexa, visto que existem diversos fatores que podem afetar o seu modo de percepção. Os usuários acabam elaborando seus próprios critérios de avaliação, vinculando juízo de valores, positivos ou negativos, frente às experiências vividas (COIMBRA et al., 2011; CARDOSO; OLIVEIRA; PIANI, 2016).

Dessa forma o atendimento recebido nas USFs, seja referente a demandas clínicas ou específicas da área de saúde mental foi relatado como experiências positivas em relação ao atendimento recebido, de acordo com as expectativas da assistência que procuram.

Bem, graças a Deus, na minha comunidade eu me dou muito bem com o grupo de enfermagem, todos os funcionários, porque ali eu sou homem que estou ali no dia a dia e não tenho problema nenhum com eles, então eles sempre me trataram bem. (P04)

Sempre eles (funcionários) me atenderam bem no posto [...], aferia a minha pressão direitinho, porque...a pessoa quando ela tá assim com esse problema mental, às vezes ela coloca coisas na cabeça né, aí fica "ai, a minha pressão tá alta" e, fica com aquela coisa, aí eu ia lá, eles aferiam direitinho, anotava meu nome e tudo, mandava eu descansar direitinho. (P -06)

A visão positiva do tratamento recebido nos serviços de saúde, como evidenciado acima, contribui para que estes sejam vistos como um suporte social para os sujeitos, suporte

Cidadania em Ação: Revista de Extensão e Cultura, Florianópolis (SC), v. 2, n.2, jul./dez. 2018. 
esse, que é crucial para a inclusão social, principalmente para os indivíduos com transtornos mentais.

Os indivíduos fazem parte de múltiplas comunidades e, é a partir desse relacionamento que eles são capazes de se redefinirem, independente da sua condição mental. O modo como esse relacionamento ocorre na comunidade, inclusive na do serviço de saúde, reflete na forma da sociedade incluir essa população e na autopercepção do sujeito sobre o acolhimento e o sentimento de pertencimento a esse corpo social (SALLES; BARROS, 2013).

Entretanto, alguns entrevistados julgaram suas experiências também como negativas, relatando não gostar do atendimento recebido. Nesses discursos, é possível perceber que as queixas e a insatisfação são voltadas às relações sociais conflituosas entre profissionais e usuários, o que acaba refletindo de forma negativa na visão desses em relação à assistência.

Não tem médico. [...] Ah! É sempre a mesma coisa, é sempre a mesma coisa. Não tem, não tem, não tem e só isso. [...] Só dizem que não tem médico e acabou. Não fazem mais nada, nem parece que tem outras pessoas que trabalham lá. (P-07)

\begin{abstract}
Sempre que eu chego lá eu sou tratada muito mal. [...] Tem as vezes que ela (a médica) diz que é pra eu chegar lá e falar com ela, mas as enfermeiras elas mentem e me tratam muito mal, sabe? [...] Eu falo assim [...] "tanta enfermeira e ninguém me trata bem aqui, todas me tratam mal". Mas, eu acho que o fato de não me tratar bem é porque eu tenho que ir de madrugada e, eu só chego mais tarde, eu acho que é por isso que elas me tratam mal. Só que elas não entendem que eu tomo a medicação controlada, eu queria que elas entendessem pelo menos, que eu sou usuária do CAPS, entendeu? Que eu tomo medicação forte, tenho epilepsia, entendeu? E elas não entendem isso não. [...] Falei que se eu pudesse daria meus remédios para elas tomarem, porque eu tomo quatorze remédios, sete de manhã e sete a noite, aí eu falei pra elas "se eu pudesse eu te dava meus remédios, para vocês sentirem o que eu sinto". (P-03)
\end{abstract}

Teve um dia que eu fui dormir lá, fiquei a noite toda lá para pegar a ficha cedo e, aí quando foi de manhã eu estava mal. Pedi pra mulher medir a minha pressão, a enfermeira da triagem né, e, ela não mediu minha pressão, aí eu ainda xinguei ainda né, eu não devia ter xingado, mas eu fiquei nervosa, aí xinguei ainda. (P-15)

Observa-se, a partir do relato de P-03, que a falta de sensibilidade por parte dos profissionais, sobre os efeitos causados pelas medicações psicoativas, como, por exemplo, o aumento do sono, o que dificulta os usuários acordarem muito cedo, refletem diretamente e de forma negativa na sua visão sobre o serviço.

Nesses casos, o princípio da equidade do SUS é negligenciado. Ao invés de obstaculizar o atendimento devido à questão do horário, é fundamental que os profissionais percebam esse momento como oportunidade de exercitar a inclusão de forma diferenciada, fazendo-se valer da equidade, abrindo espaço para a igualdade na assistência em saúde, priorizando as situações de

Cidadania em Ação: Revista de Extensão e Cultura, Florianópolis (SC), v. 2, n.2, jul./dez. 2018. 
acordo com as singularidades dos indivíduos (CORREIA;

BARROS; COLVERO, 2011; AOSANI; NUNES, 2013).

Já nos relatos de P-07 e P-15, é possível perceber que a insatisfação está relacionada com as relações interpessoais entre usuários e profissionais. Por esse motivo, o trabalho vivo em ato merece ênfase na natureza relacional do trabalho em saúde. Os profissionais detêm certo grau de liberdade para exercer suas ações, contudo muitos acabam, devido ao cotidiano, agindo de forma mecânica e, consequentemente, prejudicando as interações com os usuários e a forma de auxiliar a demanda que esses trazem (FRANCO; MERHY, 2012).

No que diz respeito às experiências voltadas às questões de saúde mental, apenas 03 usuários relataram já ter procurado a USF e ter tido vivências que julgaram positivas com o atendimento, 6 disseram já ter procurado, mas que as experiências que tiveram não foram boas e 6 relatam não procurar a estratégia de saúde da família por causa desse tipo de demanda.

O modelo de atenção à saúde mental, no Brasil, possui base comunitária e territorial, com o objetivo de priorizar as ações na atenção primária, reduzindo os atendimentos na atenção terciária. Aproximadamente $12 \%$ da população precisa de cuidados em saúde mental e $3 \%$ necessita de cuidados contínuos, reafirmando a importância do acompanhamento pelos serviços de atenção primária nessa área (LIMA; SICILIANI; DREHMER, 2012).

Nesse sentido, o empoderamento das questões referentes à saúde mental pela ESF é uma estratégia para implementação da Reforma Psiquiátrica e consolidação do conceito de integralidade do SUS, visando à vigilância, prevenção e promoção da saúde com o foco na pessoa e não na doença (PRATES; GARCIA; MORENO, 2013).

Seguindo essa linha, O Ministério da Saúde recomenda, no Caderno de Atenção Básica da Saúde Mental, medidas mínimas de cuidado que devem ser adotadas nos serviços da Atenção Básica, com ações e intervenções psicoeducacionais e intersetoriais, a exemplo de alocar os programas de saúde mental em diferentes serviços e utilizar novas estratégias de abordagem em saúde (BRASIL, 2013).

Os indivíduos que alegaram ter boas experiências na atenção básica em relação à saúde mental associam essa positividade ao fato dos profissionais os atenderem sem distinção, igual o fariam se fosse com outra pessoa e, com o atendimento e prescrição de medicações para aliviar os sintomas sentidos no momento.

Tem um tempo já, mas já fui. [...] Eles me atendem do mesmo jeito que tratam todo mundo, o médico, a enfermeira. Meu irmão gosta de lá também, fui com ele, eles me tratam bem, é bom ir lá. (P-12)

Cidadania em Ação: Revista de Extensão e Cultura, Florianópolis (SC), v. 2, n.2, jul./dez. 2018. 
Fui muito bem atendido por doutor... é até o cubano, o médico, ele me acompanhou algumas vezes, por falta de médicos aqui no CAPS. (P-04)

Uma vez eu fui ao posto [...] e quem me atendeu foi o doutor [...], que faz preventivo, no caso porque lá havia uma pessoa que me conhecia né e, aí essa pessoa se compadeceu da minha situação, do meu sistema nervoso. Ela solicitou um atendimento pra o doutor pra mim, aí o doutor passou pra mim um remédio controlado [...]. (P-06)

Esses discursos estão em consonância com o que é abordado na literatura, que traz que os profissionais que não são especialistas em saúde mental, a exemplo dos profissionais da atenção primária a saúde, tem papel fundamental na promoção dos direitos aos indivíduos com transtorno mental e são pilares para a qualificação assistencial (WENCESLAU; ORTEGA, 2015).

Ainda de acordo com esses autores, são elencados na literatura estudos que refletem que, após participação em programas educativos, os médicos da atenção primária passaram a desempenhar assistências aos indivíduos com transtornos mentais de forma hábil. Nesse sentido, o fundamental é não deixar usuário desamparado em seu sofrimento.

Em relação às experiências negativas, os usuários as associaram com a negação do atendimento por parte dos profissionais frente a situações agudas de sofrimento mental, sem ao menos realizar uma avaliação primária da situação e/ou fazer uma referência formal, a fim de potencializar a resolução da demanda.

Cheguei lá e me mandaram ir para o Hospital. Mandaram eu ir para o médico de emergência, que o posto não poderia resolver isso, aí meu esposo foi e teve que ir comigo no médico de urgência e emergência, no hospital. No caso de crise nunca me atenderam, eles sempre dizem que não podiam não, mesmo tendo médico na hora atendendo, eles disseram que não podiam. (P-09)

É... saúde mental eles falam que não é com eles não, que é aqui, que é no CAPS. Eles se recusam a ajudar. [...] Mas quando eu chego para falar assim nesses postos de saúde, ou no hospital, e falo assim que estou com um problema porque eu sou do médico psiquiatra e tal, eles (funcionários) não atendem, eles falam que é para vir para cá para o CAPS, eles nem escutam o que a gente tem para falar. (P-02)

Eles (equipe da ESF) sempre se recusam. Não adianta eu ir para lá (Unidade) em crise não, que eles não me atendem. [...] Eles me mandam de volta para casa. Geralmente quem me acode lá quando eu estou passando mal assim é o CRAS. [...] Já fui para o CRAS várias vezes. [...] Eles (da ESF) não falam nada. Só falam que não tem médico, sendo que a médica está lá dentro, dá vontade de meter o pé na porta, entendeu? Mas tem hora que a gente tem que tentar se controlar, mesmo nervosa, tem que tentar manter a calma. (P-03)

Pode-se perceber que há um afastamento dos serviços de atenção básica da assistência

Cidadania em Ação: Revista de Extensão e Cultura, Florianópolis (SC), v. 2, n.2, jul./dez. 2018. 
voltada a situações de saúde mental, em momentos de exacerbação aguda dos sintomas psicológicos e/ou de crise. Há a ausência de um acompanhamento desses usuários, e, consequentemente, não são adotadas medidas de prevenção contra as crises com promoção da saúde mental.

Constata-se, também, que os encaminhamentos seguem como primeira alternativa nas ações desses profissionais, sem uma avaliação das intervenções que poderiam ser tomadas nesse serviço a fim de auxiliar na resolução do problema do usuário. Muitos não consideram tratar ou acolher o usuário nas suas demandas de sofrimento psíquico, denotando

"incapacidade" para tal, ou relacionando o sofrimento como algo fora do seu campo de atuação, sendo a função apenas dos psicólogos ou psiquiatras.

Esse tipo de atitude vai de encontro ao que preconiza a Política Nacional de Atenção Básica, que é ser a porta de entrada dos serviços de saúde, afastando ainda mais a saúde mental das ações desse setor e os seus usuários (BRASIL, 2012).

As diretrizes da Política Nacional de Saúde Mental preveem uma cadeia de ações no nível da atenção básica a saúde. Contudo, os usuários são frequentemente redirecionados, quase que automaticamente, a outros serviços especializados, com consequente falta de responsabilização pelo serviço da atenção básica e pelos profissionais em relação ao acompanhamento da demanda mental (FRATESCHI; CARDOSO, 2014).

Essa falta de acompanhamento e de corresponsabilização não é favorável ao tratamento do usuário, que arca, praticamente sozinho ou com o apoio da família, com seu sofrimento.

Por serem complexas em várias situações, as necessidades em saúde mental, podem precisar de um acompanhamento com outros serviços, a fim de trazer benefícios e satisfação ao usuário. Contudo, este tem que sair do nível de atenção primária com a certeza de que a equipe da ESF tomou todas as medidas que lhe cabiam na intenção de resolver seus problemas e, não com a sensação de abandono (COIMBRA et al., 2011; JORGE et al., 2014).

É elevado o número de relatos na literatura evidenciando que as ações profissionais da ESF ainda hoje seguem o modelo de atenção biomédico, com ênfase na medicalização e no encaminhamento para outro nível de atenção (CAMPOS; AMARANTE, 2015).

$\mathrm{Na}$ tentativa de reverter esse quadro, tem-se utilizado como ferramenta o apoio matricial envolvendo a USF, o Núcleo de Apoio a Saúde da Família (NASF), o CAPS, entre outros, objetivando inverter o sistema tradicional de encaminhamentos indiscriminados, através da capacitação da equipe da ESF para assistir a sua população, e, consequentemente, aumentar a

Cidadania em Ação: Revista de Extensão e Cultura, Florianópolis (SC), v. 2, n.2, jul./dez. 2018. 
sua capacidade resolutiva na área da saúde mental (PRATES; GARCIA; MORENO, 2013; WENCESLAU; ORTEGA, 2015).

Contudo, há ainda aqueles indivíduos que não procuram a USF como porta de entrada da assistência em saúde mental por desconhecer essa função do serviço ou por ter criado um vínculo de cuidado com outros setores. Os usuários preferem recorrer a eles nos momentos de necessidade, ou, até mesmo, por não reconhecer USF como promotora de cuidado em saúde mental. Isso pôde ser evidenciado através dos relatos a seguir:

\footnotetext{
No lado mental eu nunca fui ao posto não, só por outros atendimentos. [...] Eu achava que só quem atendia de coisa de mental era aqui no CAPS ou no particular. Mental nunca procurei o posto não. Eu já fui atendida no Hospital. (P-05)
}

Nunca fui ao posto por causa disso, procuro só aqui no CAPS. Eu gosto daqui, me sinto bem aqui. (P-11)

No posto eu nunca cheguei a ir não por causa de questão mental assim. [...] Porque eu sabia que não era motivo de posto de saúde, sabia que só serviria o CAPS, que nesse caso só serviria o CAPS. (P-08)

Nunca fui não ao posto da família por causa do lado mental. [...] Porque eu sempre vim aqui no CAPS, lá eu vou quando vou atrás de outras coisas, então não preciso ir lá por causa disso. $(\mathrm{P}-01)$

Ressalta-se que esses sujeitos têm conhecimento dos seus direitos enquanto cidadãos, visto que participam frequentemente de rodas de conversas no CAPS. Entretanto, como evidenciado nas falas acima, o conhecimento sobre seu direito de serem acompanhados pela atenção básica em todas as suas demandas, inclusive a de saúde mental, ainda é falho.

Essa falta de compreensão, assim como o sofrimento constante de preconceito e discriminação nos serviços não especializados, e ausência de uma atenção continuada, contribuem para que os usuários não identifiquem as unidades de atenção básica como serviços de referência para o cuidado em saúde mental (FRATESCHI; CARDOSO, 2014). As principais consequências disso vão desde a desassistência, como já citado anteriormente, à sobrecarga dos serviços especializados, como CAPS e hospitais.

A sobrecarga, assim como ao encaminhamento constante de forma indiscriminada, leva a um estrangulamento dos serviços especializados, no qual os profissionais se veem com uma grande quantidade de pacientes para atender, mas sem conseguir responder a todos. Isso gera insatisfação quanto ao funcionamento da rede de apoio e o serviço passa a não ser tão resolutivo em suas potencialidades quanto poderia ser. Consequentemente, para o usuário, pode levar a um aumento do surgimento de crises e recidivas, aumentando assim a demanda em assistência

Cidadania em Ação: Revista de Extensão e Cultura, Florianópolis (SC), v. 2, n.2, jul./dez. 2018. 
mental nos serviços de emergência dos hospitais (LIMA; SICILIANI; DREHMER, 2012).

Nesse sentido, faz-se imprescindível que os serviços já existentes na rede sejam explorados de maneira adequada, cada qual exercendo com competência as suas potencialidades e que estes favoreçam a participação social ativa do usuário, para que além de ser incluído no seu próprio processo de tratamento, ele saiba contribuir com a correspondência adequada entre as suas necessidades e a oferta dos serviços (FRATESCHI;

CARDOSO, 2014).

\section{CATEGORIA 2: Facilidades e dificuldades que corroboram na qualidade da assistência}

\section{na visão dos usuários}

Os usuários dos serviços de saúde estão constantemente realizando diagnóstico e avaliação da assistência recebida com base nas suas vivências pessoais, emitindo juízo de valor sobre o que consideram bom ou ruim, ou seja, a insatisfação ou satisfação desses indivíduos são reflexos dos cuidados oferecidos pelo serviço. Essa avaliação fornece informações essenciais para a avaliação em saúde (COIMBRA et al., 2011; FRATESCHI; CARDOSO, 2014; CAMPOS et al., 2014).

Como facilidades foram mencionadas a educação e alegria por parte de alguns profissionais e o conhecimento sobre o fluxo do serviço como forma de agilizar o atendimento.

Eles são educados, isso faz bem. A gente ter que esperar com educação é melhor que ouvir mau humor. (P-12)

A alegria ajuda, porque trabalhar chateado não dá certo, só com alegria e satisfação pelo trabalho. (P-08)

Oh! Eu...é...são as hierarquias né, por que isso... se você tem um conhecimento, você vai... assim, a pessoa pega, tem aquele conhecimento ali e fala "não, vou preparar a ficha pra fulano". (P-14)

Mais uma vez, é possível perceber nos discursos que os sujeitos da pesquisa frisam a importância das relações interpessoais com os profissionais como facilitadoras da assistência em saúde.

No nível micropolítica, o atendimento cuidadoso, que perpassa pelo tratamento respeitoso, pelo interesse do profissional pelo estado de saúde do usuário, pelas explicações das dúvidas que este venha a ter, dentre outros, são dados relevantes para que o usuário demonstre satisfação com o serviço (LIMA; SICILIANI; DREHMER, 2012; JORGE et al., 2014).

Dentre as dificuldades que afetam a qualidade da assistência, as mais citadas foram: falta de médico, referência e contra referência deficiente, falta de conhecimento em saúde

Cidadania em Ação: Revista de Extensão e Cultura, Florianópolis (SC), v. 2, n.2, jul./dez. 2018. 
mental por parte dos profissionais, demora na entrega dos resultados de exames, recusa no atendimento, alta demanda de atendimento e falta de educação.

\begin{abstract}
Acho que o encaminhamento. Porque se tivesse esse encaminhamento bom seria mais fácil, porque às vezes o pessoal do posto tem contato com o pessoal daqui do CAPS, aí ficaria bem mais fácil, os dois trabalhando juntos. (P-05) Eles falam: "Ah! Esse remédio... a gente não sabe lidar com esse tipo de remédio", então eles ficam um pouco dificultando a me dar a receita e atender e tal. [...] Aí eles lá, o posto, me dificulta, me dificulta muito.(P-09)
\end{abstract}

Muitas vezes as pessoas faziam um exame e o exame voltava para o posto e para os agentes comunitários e, a gente quando ia levar para o médico já tinha passado da data, então muitas pessoas se prejudicaram e chegou até a problemas de óbito né, negligência do serviço. (P-04)

Sempre tem um pouco de dificuldade no posto [...] uma vez tinham vários médicos, aí a recepcionista falou "esse médico não vai te atender, ele não vai passar sua receita", aí eu falei "mas eu quero assim mesmo ir lá passar por ele", aí eu entrei na sala dele e ele disse que não ia me atender e nem passar aqueles remédios não, aí a atendente, boazinha, ela disse assim "mas espere mais tarde que aquele outro médico vai te atender", ela já tinha me dito que nem adiantava fazer minha ficha que aquele outro médico não ia me atender, nem dar o remédio nem nada, mas eu como estava muito precisando. (P-10)

E elas (funcionárias) deviam tratar a gente melhor né, porque elas trabalham e a gente precisa... e elas trabalham para gente, nós pagamos nossos impostos e tudo mais, então só queremos que trate a gente melhor. (P-09)

Eu acharia que a gente tinha que ter mais respeito né, carinho né, como a gente é usuário deveria ser tratado com mais respeito, entendeu? Com mais atenção. Eu já liguei até para a rádio falando sobre isso, pois a gente não tem. A gente que toma remédio controlado, a gente que é usuário não recebe respeito nenhum, é tratado como se fosse um qualquer. (P-03)

Essas dificuldades estão em consonância com as apontadas na literatura como fatores impeditivos para uma boa assistência na visão dos usuários, sendo elas: sobrecarga de trabalho, ausência de uma rede estruturada de referência e contra referência, despreparo dos trabalhadores para lidar com a saúde mental, perpetuação do modelo biomédico, filas, dificuldade para a obtenção da ficha para consulta, desorganização da demanda, número insuficiente de médicos e enfermeiros, entre outros (JUNQUEIRA; PILLON, 2011; LIMA; SICILIANI; DREHMER, 2012; FRATESCHI; CARDOSO, 2014).

Ainda há uma dificuldade em destaque, que contribui para a insatisfação dos usuários: a dificuldade de acesso ao serviço por usuários que não fazem parte dos programas, como prénatal e acompanhamento de hipertensos e diabéticos (COIMBRA et al., 2011). O que reforça a importância de se implantar estratégias voltadas à promoção, proteção e acompanhamentoda

Cidadania em Ação: Revista de Extensão e Cultura, Florianópolis (SC), v. 2, n.2, jul./dez. 2018. 
saúde mental na ESF, o que ainda hoje aparece raramente nos estudos na literatura (JUNQUEIRA; PILLON, 2011).

No que diz respeito à falta de conhecimento em saúde mental e a recusa no atendimento, a falta de preparo, seja emocional ou profissional, é apontada como travamento para o cuidado amplo aos usuários com esse tipo de demanda, seja por medo, discriminação ou sentimento de incapacidade por parte dos profissionais (LIMA; SICILIANI; DREHMER, 2012). Evidencia-se assim, mais uma vez, a importância de incentivar a formação em saúde mental da equipe, para que os profissionais aprendam sobre os cuidados nessa área e sintamse seguros, deixando de lado todas as ressalvas que impedem a realização do atendimento integral e contínuo.

A referência e contra referência deficiente é reflexo da persistência do modelo medicalizante, contudo, o ato de cuidar não se limita a administração de medicamentos e a encaminhamentos quando a temática não for de completo domínio do serviço (FRATESCHI; CARDOSO, 2014). É preciso que cada profissional busque apreender novos conhecimentos constantemente, para que seja possível acolher o usuário, formar vínculo e proporcionar um cuidado humanizado, permanente e integral.

\section{CONSIDERAÇÕES FINAIS}

As equipes de Estratégia de Saúde da Família são primordiais para o acompanhamento em situações de sofrimento psíquico, contudo, ficou evidenciado que os usuários percebem que esse serviço não está preparado para atender as suas demandas em saúde mental e que as suas demandas clínicas sofrem bastante influência da formação do vínculo com os profissionais para serem atendidas ou não.

O modelo de assistência proposto pela RAPS, com inclusão da assistência em saúde mental na atenção básica, ainda não está sendo executado em sua totalidade, evidenciando que há muitas lacunas a serem preenchidas em busca da sua implementação de forma satisfatória.

Algumas das lacunas são a pouca produção científica sobre a temática e a escassez de estudos que deem voz ao usuário, que é peça chave para o planejamento e execução da assistência à saúde. Percebe-se, também, uma desarticulação da gestão em relação à efetivação das ações em saúde na atenção básica.

Essa situação resulta, muitas vezes, no afastamento dos sujeitos e no não reconhecimento desse serviço, em sua maioria, como uma referência para o acompanhamento do seu tratamento.

Cidadania em Ação: Revista de Extensão e Cultura, Florianópolis (SC), v. 2, n.2, jul./dez. 2018. 


\section{REFERÊNCIA}

AOSANI, T. R.; NUNES, K. G. A Saúde Mental na Atenção Básica: A percepção dos Profissionais de Saúde. Revista Psicologia e Saúde, v. 5, n. 2, p. 71-80, jul./dez. , 2013.

BARDIN, L. Análise de conteúdo. 5.ed. [S.L.]: Edições 70, 2009.

BRASIL. Ministério da Saúde. Secretaria de Atenção à Saúde. Departamento de Atenção Básica. Cadernos de Atenção Básica Saúde mental. Brasília, 2013.

BRASIL. Ministério da Saúde. Secretaria de Atenção à Saúde. Departamento de Atenção Básica. Política Nacional de Atenção Básica. Brasília: Ministério da Saúde, 2012.

CAMPOS, R. T. O.; et al. Avaliação da qualidade do acesso na atenção primária de uma grande cidade brasileira na perspectiva dos usuários. Saúde Debate, Rio de Janeiro, v.38, n. especial, p. 252-264, out., 2014.

CAMPOS JÚNIOR, A.; AMARANTE, P.D.C. Estudo sobre práticas de cuidado em saúde mental na Atenção Primária: o caso de um município do interior do estado do Rio de Janeiro.

Cad. Saúde Colet., v.23, n.4, p. 425-435, 2015.

CARDOSO, M.R.O.; OLIVEIRA, P.T.R.; PIANI, P.P.F. Práticas de cuidado em saúde mental na voz dos usuários de um Centro de Atenção Psicossocial do estado do Pará. Saúde Debate, v.40, n.109, p. 86-99, jun., 2016.

COIMBRA, V. C. C.; et al. Avaliação da satisfação dos usuários com o cuidado da saúde mental na Estratégia Saúde da Família. Revista da Escola de Enfermagem USP, v.45, n.5, p. 1150-1156, 2011.

CORREIA, V. R.; BARROS, S.; COLVERO, L. A. Saúde mental na atenção básica: prática da equipe de saúde da família. Revista da Escola de Enfermagem USP, v.45, n.6, p. 15011506, 2011.

FRANCO, T. B.; MERHY, E. E. Cartografias do Trabalho e Cuidado em Saúde. Revista Tempus Actas de Saúde Coletiva, Brasília DF, v. 6, n. 2, p. 151-163, 2012.

FRATESCHI, M. S.; CARDOSO, C. L. Saúde Mental na Atenção Primária à Saúde: avaliação sob a ótica dos usuários. Physis Revista de Saúde Coletiva, Rio de Janeiro, v.24, n.2, p. 545-565, 2014.

JORGE, M. S. B.; et al. Resolubilidade do cuidado em saúde mental na Estratégia Saúde da Família: representação social de profissionais e usuários. Revista da Escola de Enfermagem USP, v.48, n.6, p.1062-1068, 2014. 
JUNQUEIRA, M. A. B.; PILLON, S. C. A assistência em saúde mental na estratégia saúde da família: uma revisão de literatura. Revista de Enfermagem do Centro-Oeste Mineiro., v.1, n.2, p.260-267, abr./jun., 2011.

LIMA, F. G.; SICILIANI, C. C.; DREHMER, L. B. R. O perfil atual da saúde mental na atenção primária brasileira. Comunicação em ciências da saúde, v.24, n.2, p. 143-148, 2012.

PRATES; M. M. L.; GARCIA, V. G.; MORENO, D. M. F. C. Equipe de apoio e a construção coletiva do trabalho em Saúde Mental junto à Estratégia de Saúde da Família: espaço de discussão e de cuidado. Saúde e Sociedade, São Paulo, v.22, n.2, p.642-652, 2013.

SALLES, M. M.; BARROS, S. Inclusão social de pessoas com transtornos mentais: a construção de redes sociais na vida cotidiana. Ciência \& Saúde Coletiva, v.18, n.7, p. $21292138,2013$.

TANAKA, O. Y.; RIBEIRO, E. L. Ações de saúde mental na atenção básica: cami-nho para ampliação da integralidade da atenção. Ciência \& Saúde Coletiva, v.14, n.2, p.477-486, 2009.

WENCESLAU, L. D.; ORTEGA, F. Saúde mental na atenção primária e Saúde Mental Global: perspectivas internacionais e cenário brasileiro. Interface - Comunicação, Saúde, Educação, Botucatu, v.19, n.55, p.1121-1132, 2015. Disponível em:

$<$ http://www.scielo.br/readcube/epdf.php?doi=10.1590/1807-

57622014.1152\&pid=S141432832015000401121\&pdf_path=icse/v19n55/1807-5762-icse1807-576220141152.p df\&lang=pt>. Acesso em: 07 set. 2017. 